\title{
Personality predictors of driver vengeance
}

\author{
Wickens, C. M., Wiesenthal, D. L., \& Roseborough, J. E. W.
}

Version Post-Print/Accepted Manuscript

Citation Wickens, C. M., Wiesenthal, D. L., \& Roseborough, J. E. W. (2015).

(published version) Personality predictors of driver vengeance. Violence and Victims. 30(1), 148-162.

Publisher's Statement The final publication is available at Springer via http://dx.doi.org/10.1891/0886-6708.VV-D-13-00111. 
Running head: DRIVER VENGEANCE

\title{
Personality Predictors of Driver Vengeance
}

\author{
Christine M. Wickens ${ }^{1}$, David L. Wiesenthal ${ }^{2}$, James E. W. Roseborough ${ }^{2}$ \\ ${ }^{1}$ Centre for Addiction and Mental Health, Toronto, Canada \\ ${ }^{2}$ York University, Toronto, Canada
}

Correspondence concerning this article should be addressed to:

Dr. Christine M. Wickens

Centre for Addiction and Mental Health

Social and Epidemiological Research Department

33 Russell Street, T417

Toronto, Ontario M5S 2S1

Canada

Email: Christine.Wickens@camh.ca

Tel: 416-535-8501 ext. 4711

Fax: 416-595-6899 


\begin{abstract}
The purpose of the current study was to identify personality and individual difference measures related to driver vengeance, as measured by the Driver Vengeance Questionnaire (DVQ; Wiesenthal, Hennessy, \& Gibson, 2000). There were 170 undergraduate students completed paperand-pencil questionnaires including the DVQ and measures of narcissism, impulsivity, and trait driver stress. A hierarchical linear regression predicting DVQ score revealed that being male $(\beta=$ $.25)$, narcissism $(\beta=.19)$, and trait driver stress $(\beta=.41)$ were significantly associated with vengeance. Impulsivity was significant in the third block of the regression but was not a significant predictor of vengeance in the final block. Interactions between gender and the individual difference measures were not significant. The final model accounted for $34 \%$ of the variance. Implications of the results and directions for future research are discussed.
\end{abstract}


In the general aggression literature, vengeance is defined as the infliction of harm for a perceived injustice and is considered to be a motivating factor for aggressive behavior. Vengeful individuals feel justified harming others whose actions are perceived as warranting punishment or correction (Hennessy \& Wiesenthal, 2005a; Stuckless \& Goranson, 1992). Vengeful acts typically pursue one of three subsidiary goals: (a) "getting even" (i.e., an "eye for an eye"); (b) moral instruction (i.e., teaching the perceived offender a lesson), and; (c) "saving face" to establish respect from the perceived offender and possible witnesses (McCullough, Bellah, Kilpatrick, \& Johnson, 2001). The latter goal may also increase the vengeful individual's self-worth (CotaMcKinley, Woody, \& Bell, 2001). Vengeful individuals tend to be less forgiving of interpersonal offenses, ruminate more about offenses, and are motivated to seek revenge for a longer period of time than less vengeful individuals (McCullough et al., 2001).

\section{VENGEANCE IN THE ROADWAY ENVIRONMENT}

The roadway environment is vulnerable to vengeful acts for several reasons. First, the roadway environment is a social setting, with rules and norms for appropriate behavior (Rothe, 1994). Violations of these formal and informal rules and norms can result in significant anger and possibly vengeful reactions. Second, motorists often perceive their vehicle as personal space or territory, which is valued as defensible when threatened (Marsh \& Collett, 1987). Third, the potential consequences of roadway violations include significant financial cost, injury, and death. When the possible impact of someone else's misbehavior is more serious or threatening, the victim's anger in response to the misbehavior is likely to be intensified (Cota-McKinley et al., 2001). Fourth, a vehicle provides its driver with a degree of anonymity, reducing the risk of identification by others and essentially freeing the driver from potential evaluation, criticism, judgment, or punishment (Ellison, Govern, Petri, \& Figler, 1995; Ellison-Potter, Bell, \&

Deffenbacher, 2001). For the female driver, this anonymity may reduce the pressure to conform to 
the typical female gender role, which normally restrains aggressive tendencies in women (Eagly \& Steffen, 1986; Hennessy, Wiesenthal, Wickens, \& Lustman, 2004). Fifth, for the urban driver negotiating crowded roads, it is unlikely that the driver will encounter the surrounding motorists in future trips (Hennessy \& Wiesenthal, 2005b), thus reducing any inhibitory tendencies.

Driver diary studies have been conducted to estimate the frequency of roadway anger. These studies typically ask motorists to report the number and types of roadway offenses that they encounter, and the resulting frequency estimates of reported anger have varied greatly. In a British study, approximately $85 \%$ of participants experienced anger at least once over a 2 -week period; overall, participants expressed anger in about one-fifth of all trips taken (Underwood, Chapman, Wright, \& Crundall, 1999). In a Canadian study, $87 \%$ of driver diaries reported at least a minor anger-provoking event involving another motorist over a 48-hour period (Wickens, Roseborough, Hall, \& Wiesenthal, 2013; Wickens, Wiesenthal, Flora, \& Flett, 2011). In an American study, over a 10-day period, drivers expressed roadway anger at least daily (Neighbors, Vietor, \& Knee, 2002). A Dutch study asked participants to report their emotions aloud to a passenger experimenter during a single 50-minute commute. Anger was reported an average of 1.5 times (Mesken, Hagenzieker, Rothengatter, \& De Waard, 2007). Fortunately, not all drivers who experience roadway anger will express their emotions through aggression (Wickens, Wiesenthal, et al., 2011). Much of the scientific research examining driver safety has focused on identifying those drivers who are more likely to perpetrate an aggressive roadway behaviour, which is often motivated by a need for revenge.

According to Wiesenthal et al. (2000), vengeful drivers are disposed to purposely harm other motorists who are perceived to have committed an injustice against them. Harm inflicted by vengeful drivers may include physical or psychological pain, injury, emotional harm, humiliation, or annoyance (Hennessy \& Wiesenthal, 2005a). To expand our understanding of driver vengeance 
in response to offensive driving situations, Wiesenthal and colleagues developed the Driver Vengeance Questionnaire (DVQ; Hennessy \& Wiesenthal, 2001a; Wiesenthal et al., 2000). The DVQ assesses drivers' reactions to perceived threats and identifies which situations elicit the strongest reactions. Driving vengeance, as measured by the DVQ, is typically greater in males than females and greater in younger than older drivers (Hennessy \& Wiesenthal, 2002a, 2002b, 2005a; Li, Li, Long, Zhan, \& Hennessy, 2004; Wiesenthal et al., 2000). Vengeance has been associated with higher levels of anger in response to hypothetical roadway altercations (Li et al., 2004; Lustman, Wiesenthal, \& Flett, 2010). Vengeful drivers are more likely to perceive ambiguous or minor infractions by other roadway users as a personal affront (Lustman et al., 2010), which has been shown to result in increased anger and aggression. Vengeance has been linked to roadway aggression and violence in both questionnaire studies inquiring about past roadway behaviour (e.g., Hennessy \& Wiesenthal, 2002a, 2002b; Wiesenthal et al., 2000) and in field studies conducted in the actual driving environment (e.g., Hennessy \& Wiesenthal, 2001a). These associations between driver vengeance and driver anger, aggression, and violence have been demonstrated not only in Canada, where the DVQ was developed, but also internationally, including Italy (Hennessy, Wiesenthal, \& Piccione, 2001), Poland (Przepiórka, Blachnio, \& Wiesenthal, 2014), Russia (Hennessy, 2013), and China (Li et al., 2004)

Previous research has also identified important interactions between driver vengeance and driving-related individual differences when predicting roadway aggression. For instance, in the driving environment, a motorist's perception of personal space may include the area immediately surrounding the vehicle, to provide a means of buffering or regulating one's own safety as well as the physical and financial protection of the vehicle. A preference for greater "driver space" has been found to interact with vengeance such that, at higher levels of vengeance, driver aggression by motorists with low and moderate driver space preferences increased to match the levels of 
aggression reported by those with a high driver space preference (Hennessy, 2013). Likewise, driver aggression has generally been found to decline with increasing age (Wickens, Mann, Stoduto, Ialomiteanu, \& Smart, 2011); however, among high-vengeance drivers, self-reported driver aggression appears to increase with age (Hennessy \& Wiesenthal, 2004). A sense of perceived control over the driving environment has also been found to interact with driver vengeance, demonstrating a buffering effect against aggression in heavy traffic, even among highly vengeful drivers (Hennessy, 2008). These findings demonstrate the importance of fully exploring the relationship between driver vengeance and individual differences relevant to the roadway environment.

Beyond these associations between driver vengeance and dangerous roadway behavior, there is little known about the attitudinal and personality correlates of driver vengeance. How do other individual difference variables relate to driver vengeance? Lustman and colleagues (2010) presented participants with 10 written vignettes describing common frustrating driving situations in which the offending motorist's actions could be interpreted as benign or ambiguous. Participants were asked to indicate the degree to which they would perceive the offending motorist's actions as intentional, inconsiderate, and personally directed and the extent to which they would feel anger in response to the driving event. Participants also completed a battery of personality measures, including a measure of narcissism and the DVQ. Results identified a positive correlation between vengeance and narcissism for both males and females.

Narcissism is a pervasive pattern of grandiosity and need for admiration. Narcissistic individuals have a positive but fragile self-image and are motivated to maximize their self-esteem to validate their grandiose self-image (Bushman \& Baumeister, 1998). Therefore, narcissistic individuals tend to react with rage, shame, or humiliation when they feel they have been insulted (Rhodewalt \& Morf, 1998). It would follow that they would also have a tendency to hold more 
vengeful attitudes toward and react more vengefully in response to perceived roadway offenses. Interestingly, when predicting driver aggression in response to the driving scenarios, Lustman et al. (2010) found an interaction between gender and narcissism. The authors suggested that men high in narcissism may not differ significantly from men low in narcissism in terms of their aggressive tendencies on roadways, unless the other motorist's offensive actions tap into the narcissist's need for vengeance. However, vengeance may not be as influential in heightening the female narcissist's aggressive responses. Women high in narcissism reported more driver aggression in response to the frustrating driving scenarios, regardless of whether the other motorist's actions tap into the narcissist's need for vengeance.

\section{PREDICTORS F DRIVER ANGER AND AGGRESSION}

To more fully understand driver vengeance, further study of its correlates and predictors is needed, including more general attitudinal and personality variables. In light of the relationship between driver vengeance and driver anger, aggression, and violence, consideration of individual difference variables associated with these latter driving-related constructs represents a reasonable first step in furthering our knowledge of how vengeance contributes to roadway altercations (Wiesenthal, Lustman \& Roseborough, in press).

In addition to Lustman and colleagues' (2010) findings, other studies have identified associations between narcissism and roadway anger and aggression. Schreer (2002) found that exhibitionism and entitlement, two subscales of the Narcissistic Personality Inventory (Raskin \& Terry, 1988), predicted driver aggression. Britt and Garrity (2006) found that narcissism was a significant predictor of driver anger when following a slow-moving vehicle. Finally, Roseborough, Wiesenthal, Flett, and Cribbie (2011) presented undergraduate students with written vignettes and animated clips describing unjust driving events. A structural equation model identified a direct relationship between narcissism and anticipated driver aggression in response to the unjust 
scenarios. This group of results is consistent with the theory of threatened egotism, which states that individuals holding an inflated self-image are more likely to aggress when their self-image is threatened.

Impulsivity has been associated with risky driving behaviour and roadway violations (e.g., speeding, running a yellow light) as well as driver aggression (Dahlen, Martin, Ragan, \& Kuhlman, 2005; DePasquale, Geller, Clarke, \& Littleton, 2001; O’Brien \& Gormley, 2013; Wickens, Toplak, \& Wiesenthal, 2008). When tested on the go-no go task, a behavioural measure of impulsivity, drivers convicted of speeding demonstrated faster reaction times but committed more errors than drivers with no roadway convictions (O’Brien \& Gormley, 2013). Impaired impulse control is also a primary symptom of attention deficit hyperactivity disorder, which has been associated with increased crash frequency, traffic citations, risk-taking, and driver aggression (Barkley \& Cox, 2007).

Driver stress is experienced when a motorist perceives a driving situation as demanding or dangerous. Driver stress can result in emotional responses such as anxiety and frustration (Gulian, Matthews, Glendon, Davies, \& Debney, 1989) or in psychophysiological responses such as increased blood pressure and muscle tension (Malta et al., 2001). Driver stress can be conceptualized as a state- or trait-level construct. State driver stress is specific to a given driving situation, whereas trait driver stress reflects an accumulation of negative feelings and frustrations related to driving generally (Gulian et al., 1989). High trait stress drivers demonstrate reduced control skills and increased errors when following another vehicle (Matthews et al., 1998), and are involved in more traffic collisions (Matthews, Dorn, \& Glendon, 1991). They also exhibit more driver aggression including tailgating, swearing/yelling, and obscene hand gestures (Hennessy \& Wiesenthal, 2001b), possibly a result of their increased likelihood of perceiving other drivers as the source of frustration (Gulian et al., 1989). 
Gender has also been identified as an important consideration in the study of driver behavior. Males have been found to report both driver vengeance and driver violence (Hennessy, 2013; Hennessy \& Wiesenthal, 2002a, 2002b, 2005a; Hennessy et al., 2004; Wiesenthal et al., 2000). Gender has also been found to interact with individual difference variables in the prediction of negative driving outcomes. As stated previously, Lustman et al. (2010) reported a significant interaction between gender and narcissism in the prediction of driver aggression, indicating that among individuals low in narcissism, males reacted more aggressively than females, but among individuals high in narcissism the reverse was true. Lustman et al. also reported a significant interaction between gender and anger in the prediction of driver aggression, indicating that males reacted more aggressively to roadway frustrations than females at elevated levels of anger, whereas females reacted more aggressively at lower levels of anger. Hennessy and Wiesenthal (2005a) found a significant interaction between gender, vengeance, and driving violations in the prediction of driver violence, such that violence increased in male drivers with a vengeful attitude, especially in combination with higher levels of violations. These findings demonstrate the importance of controlling for the effects of gender and assessing its potential interaction with other individual difference variables in the prediction of driver violence and related constructs,

\section{PURPOSE}

In light of the limited available driver vengeance research, this study was designed to identify other personality traits and individual differences related to driver vengeance. Narcissism, impulsivity, and trait driver stress are three such constructs previously identified as predictors of mild driver aggression and driver violence. The current study selected these three constructs to identify each of their unique contributions to the prediction of driver vengeance. Controlling for the impact of gender, it was hypothesized that greater levels of narcissism, impulsivity, and trait driver stress would predict higher levels of driver vengeance. It was anticipated that males would 
report greater levels of driver vengeance, but no specific hypotheses concerning the interaction of gender with the individual difference variables were postulated.

\section{METHOD}

\section{Participants}

A sample of 170 undergraduate students $(70=$ male, $100=$ female $)$ were recruited to participate in a study of thoughts and feelings about driving. Participants were obtained using the York University undergraduate research participant pool and through on-campus in-person recruitment. Participants ranged in age from 17 to 51 years old $(M=23.8, S D=6.34)$. Participant license possession ranged from 11 months to 29 years $(M=6$ years and 5 months, $S D=4$ years and 9 months). Participants reported driving 6 out of 7 days per week on average ( $S D=1$ day), spending a mean of $11 \mathrm{hr}$ and $49 \mathrm{~min}$ in their vehicles per week ( $S D=10 \mathrm{hr}$ and $49 \mathrm{~min}$ ), and travelling a mean distance of $375.8 \mathrm{~km}(S D=244.0 \mathrm{~km})$. Major highways (e.g., Highway 400, 401, 404 in Southern Ontario) were the most commonly travelled road type for 105 participants, minor highways were the most commonly travelled road type for 12 participants, and city streets were the most commonly travelled road type for 39 participants. In exchange for their participation, respondents recruited through the participant pool received course credit, whereas respondents recruited in-person on-campus received a $\$ 10$ university bookstore gift card or a certificate for a free cinema movie. The research was approved by the university's research ethics board.

\section{Procedure and Measures}

Participants completed a battery of paper-and-pencil self-report questionnaires.

Driving Vengeance Questionnaire. Designed to assess drivers' use of vengeance when faced with common driving situations, the DVQ (Wiesenthal et al., 2000) presents 15 scenarios and asks participants to indicate the behavioral response that they would most likely make in that 
situation. For example, “After stopping at a STOP sign, a motorist fails to yield the right of way to you when it is your turn to proceed through the intersection. You would: (a) pull out quickly to block their way, (b) give the driver an obscene gesture (e.g., the finger), (c) honk your horn, (d) do nothing, (e) other (please specify).” Items are scored from 4 (i.e., most aggressive response/option “a”) to 1 (i.e., least aggressive response/option “d”). When "other" was chosen and an alternative response was provided, the alternative answer was assigned a score by determining which of the existing answer options (i.e., "a" to "d") was most similar to the alternative response and assigning an item score accordingly (i.e., 4 to 1 ). To ensure the reliability of this scoring procedure, all alternative answers were scored by two independent coders. These coders reached agreement on 509 out of 576 alternative answers, generating a Cohen's kappa of .74 and demonstrating good interrater reliability (Altman, 1991, as cited in Shin, Hallett, Chipman, Tator, \& Granton, 2005). The DVQ has previously been shown to have high internal consistency, with Cronbach's $\alpha$ ranging from .75 to .84 (Hennessy, 2008, 2013; Hennessy \& Wiesenthal, 2001a, 2002a, 2002b, 2004; Wiesenthal et al., 2000).

Narcissistic Personality Inventory. The Narcissistic Personality Inventory (NPI; Raskin \& Terry, 1988) was used to assess participants' level of narcissism. The NPI consists of 40 forcedchoice items. For each item, participants are presented two statements; one is narcissistic and one is non-narcissistic. An example of a narcissistic statement is "I think I am a special person." An example of a non-narcissistic statement is "I am no better or no worse than most people." Participants select the statement that is most representative of their typical thoughts or behaviours. Items are then summed, and higher scores indicate higher levels of narcissism. The NPI has consistently shown good internal consistency (Guttman's $\lambda 3=.83$ ) and adequate construct validity (Raskin \& Terry, 1988). 
Eysenck’s Impulsivity Questionnaire. Eysenck’s Impulsivity Questionnaire (Eysenck, Pearson, Easting, \& Allsopp, 1985) was used to assess participants' level of impulsivity. The measure consists of 19 items. Sample items include, "Do you generally do and say things without stopping to think?" and "Before making up your mind, do you consider all the advantages and disadvantages?" (reverse scored). Participants rate how often they engage in these behaviours using a 6-point Likert-type scale ranging from 0 (never) to 5 (always). Higher scores are indicative of increased impulsivity. The measure has demonstrated good reliability (Cronbach's $\alpha$ ranging from .83 to .84 ) and adequate construct validity (Eysenck et al., 1985).

Driver Behaviour Inventory - General. The Driving Behaviour Inventory-General (DBIGen; Gulian et al., 1989) assessed trait driver stress employing an 11-item version of the scale which is a valid, robust, and reliable measure of trait driver stress, with Cronbach's $\alpha$ ranging from .82 to .92 (Hennessy \& Wiesenthal, 1997; Wickens \& Wiesenthal, 2005). Sample items include, "When I try but fail to overtake I am usually frustrated," and "I lose my temper when another driver does something silly." Participants rated how much they agree with each statement using a Likert-type scale ranging from 0 (totally disagree) to 100 (totally agree). Larger scores are indicative of increased driver stress.

Collisions and Violations. Participants were asked to self-report the number of collisions they had had, the number of tickets/citations received for moving violations, and the number of demerit points received. Participants were also asked to indicate their typical speed when driving on a road with a $60-\mathrm{kph}(37.3 \mathrm{mph})$ speed limit and when driving on a highway with a $100-\mathrm{kph}$ (62.1 mph) speed limit.

\section{RESULTS}

The means, standard deviations, and reliability analysis of each of the primary measures for the total sample and by gender are provided in Table 1. Reliability of all measures was within 
acceptable range ( $\alpha>$.70; Nunnally \& Bernstein, 1994). A bivariate correlations matrix is also provided in Table 1. A series of independent sample $t$ tests and chi-square analyses revealed only one gender difference across measures. Mean DVQ score was greater among male $(\mathrm{M}=2.02, S D$ $=0.48)$ than female $(\mathrm{M}=1.80, S D=0.40)$ drivers $(t[163]=3.19, p=.002)$.

DVQ scores were examined as a function of self-reported collisions and violations. Because of the highly non-normal distribution of collision and violation counts, the number of collisions, tickets, and demerit points were recoded to binary variables $(0=$ none, $1=1$ or more $)$. Typical speeds driven on roads and highways were also recoded. The distribution of scores for these variables were bimodal or multimodal; thus, these variables were recoded into three groups (i.e., slow, medium, and fast drivers) based on speed values that coincided with the most predominant modal patterns. Therefore, the difference in speed between groups was not equal. For highways with a 100-kph speed limit, responses were recoded to 1 (up to $110 \mathrm{kph}$ ), 2 (111 to 120 $k p h$ ), and $3(121+k p h)$. For roads with a 60-kph speed limit, responses were recoded to 1 (up to $65 \mathrm{kph}), 2$ (66 to $70 \mathrm{kph})$, and $3(71+\mathrm{kph})$. Mean scores for each of these recoded variables is provided in Table 2 .

Independent sample $t$-tests revealed no significant differences in DVQ score as a function of collisions $(t[164]=-0.55, p=.58)$, tickets $(t[160.50]=-1.19, p=.24)$, or demerit points $(t[162]$ $=-1.07, p=.29$ ). A one-way analysis of variance (ANOVA) revealed significant differences in DVQ scores for typical speed on a $60-\mathrm{kph} \operatorname{road}(F[2,163]=7.38, p=.001)$ and typical speed on a 100-kph highway $(F[2,163]=5.79, p=.004)$. Post hoc comparisons using Tukey's honest significant difference (HSD) test found that in both cases, the slow drivers (i.e., up to $65 \mathrm{kph}$ and up to $110 \mathrm{kph}$ ) had significantly lower DVQ scores than the medium and fast drivers $(p=.002$ and .006 , respectively on a 60-kph road; $p=.026$ and .008 , respectively on a $100-\mathrm{kph}$ road), who did not differ significantly from each other ( $p=1.00$ on a $60-\mathrm{kph}$ road; $p=.40$ on a $100-\mathrm{kph}$ road). 
Hierarchical linear regression was conducted to identify personality and individual difference predictors of driver vengeance as measured by the DVQ. Markers for multicollinearity were assessed (Field, 2005) and were indicative of an absence of multicollinearity. Nonetheless, all main and interaction effects were centered (Aiken \& West, 1991; Tabachnick \& Fidell, 2001). Missing values were treated pairwise. Gender was entered in the first block as a control variable, with each of the primary predictor variables entered forcibly in subsequent blocks. All possible two-way interactions between gender and the primary predictors were entered stepwise in the final block, allowing the statistical software (SPSS version 15.0) to select interaction variables to be retained in the model based on accounted variance.

The final prediction model was significant, $F(4,139)=19.40, p<.001$. The adjusted $R^{2}$ indicated that the model accounted for $34 \%$ of the variance in driver vengeance. Gender was a significant predictor of vengeance $(\beta=.25, t=3.68, p<.001)$, accounting for $6 \%$ unique variation in vengeance. Males were more vengeful than females. Narcissism was a significant predictor of vengeance $(\beta=.19, t=2.61, p=.01)$, accounting for $3 \%$ unique variation. Individuals with increased levels of narcissism were more vengeful than individuals with lower levels of narcissism. Although impulsivity significantly predicted vengeance in a preliminary block of the regression, it was not significant in the final block $(\beta=.09, t=1.31, p=.192)$, and accounted for less than $1 \%$ unique variation in vengeance. Driver stress was a significant predictor $(\beta=.41, t=$ $5.26, p<.001)$ and accounted for $13 \%$ unique variation in vengeance. Individuals who reported experiencing greater driver stress also reported being more vengeful drivers. None of the two-way interactions were significant predictors of vengeance and thus were eliminated from the final model. Table 3 provides the details of the preliminary and final regression models.

\section{DISCUSSION}


Driver vengeance is associated with increased anger, mild aggression, and violence in the roadway environment (Hennessy, 2008, 2013; Hennessy \& Wiesenthal, 2001a, 2002a, 2002b; Hennessy et al., 2001; Li et al., 2004; Lustman et al., 2010; Przepiórka et al., 2014; Wiesenthal et al., 2000). In this study, although driver vengeance was not associated with increased collisions, demerit points, or tickets for moving violations, greater vengeance was associated with higher selfreported speed on both roads and highways. This may suggest that vengeful drivers are greater risk-takers or that they more strongly endorse norm violations, but their actions do not appear to have resulted in more collisions or to have been detected by law enforcement authorities. That is not to say, however, that other motorists on the roadway have not been affected by vengeful drivers' behaviors.

To date, although it is clear that a vengeful driving attitude is associated with driver anger and aggression, little is known about this construct. There has been virtually no prior research examining how vengeance relates to personality and other individual difference variables. This study was a preliminary investigation of the relationship between driver vengeance, as measured by the DVQ, and three variables previously identified as predictive of aggressive driver behavior (i.e., narcissism, impulsivity, and trait driver stress).

Gender of the driver was included as a control variable in the regression analysis. Consistent with previous research (Hennessy \& Wiesenthal, 2002a, 2002b, 2005a; Wiesenthal et al., 2000), gender was a significant predictor of driver vengeance, with males being more likely to respond vengefully to offensive roadway events. Males have generally been found to be more accepting of vengeful attitudes and interpersonal aggression (Cota-McKinley et al., 2001; Stuckless \& Goranson, 1992), and evolutionary theory suggests that males possess more evolved physiological and psychological means for effective use of aggressive behavior (Wiesenthal \& Singhal, 2012; Wilson \& Daly, 1985). Interestingly, although previous research has suggested that 
male drivers are more likely than female drivers to engage in violent roadway behaviour, no such gender difference has been found for mild driver aggression (Hennessy, 2013; Hennessy \& Wiesenthal, 2002a, 2002b; Hennessy et al., 2004). An interaction between vengeance and gender helps to explain this finding. Hennessy and Wiesenthal (2002a) reported that driver vengeance was associated with increased roadway aggression and violence in both male and female drivers. However, the impact of vengeance on driver violence was greater among male than female drivers. Narcissism was also a significant predictor of driver vengeance, with higher narcissism scores being associated with increased vengeance scores. These results are consistent with the findings of Lustman et al. (2010) who reported a positive correlation between narcissism and vengeance. Narcissistic individuals may hold more vengeful attitudes toward perceived roadway offenses. Interestingly, when predicting driver aggression, Lustman et al. reported a significant interaction between gender and narcissism and suggested that vengeance may be more influential in heightening roadway aggression among male narcissists than female narcissists. In this study, the interaction between gender and narcissism failed to predict driver vengeance, suggesting that vengeance may not explain the gender by narcissism interaction in the prediction of driver aggression found by Lustman and colleagues.

Impulsivity was positively correlated with driver vengeance and positively predicted driver vengeance in the third block of the hierarchical regression analysis. However, it was not significant in the final model, after trait driver stress had been entered. Despite the absence of multicollinearity issues, given the strong correlation between impulsivity and trait driver stress $(r$ $=.45, p<.001)$, it is likely that these variables accounted for common variance in the prediction of driver vengeance. Previous research has suggested that impulsivity is associated with aggressive (Galovski, Blanchard, \& Veazey, 2002; Smart, Mann, \& Goldbloom, 2005) and risky driving (Ryb, Dischinger, Kufera, \& Read, 2006; Wickens et al., 2008) as well as increased crash risk 
(Williams, Tregear, \& Amana, 2011). Although future research should be conducted to confirm this interpretation, it is fair to say that impulsive drivers are more likely to be vengeful in their response to other motorists who they perceive to be engaging in offensive behavior.

Finally, trait driver stress was also identified as a significant predictor of driver vengeance. Motorists who perceived driving as stressful or as a source of frustration or irritation were more likely to be vengeful drivers. Previous research has also found trait driver stress to predict state driver stress reported from inside the vehicle (Hennessy \& Wiesenthal, 1997; Wickens \& Wiesenthal, 2005), as well as mild driver aggression and driver violence (Hennessy \& Wiesenthal, 2001b).

\section{LIMITATIONS}

Several limitations of this study must be noted. First, the sample consisted predominantly of university students, possibly limiting the generalizability of the findings. Although driver vengeance is an important predictor of driver aggression at all ages (Hennessy \& Wiesenthal, 2004), aggressive roadway behavior is more prevalent among younger drivers (Wickens, Mann, et al., 2011), making the study of driver vengeance particularly relevant to this age-group. Second, the study relied entirely on self-report questionnaires, making the results correlational and common method variance a potential source of error. Nonetheless, this was an exploratory investigation of the relationship between driver vengeance and various personality and individual difference measures, and the use of self-report measures is a standard approach for this purpose (Whitley, 1996). Third, vengeance scores in the current sample were somewhat low, suggesting that the findings may not apply to the most vengeful drivers. Yet, high-vengeance drivers likely represent only a small proportion of the driving population, with the remainder possessing vengeance levels similar to those found in this study. Future research examining drivers with more extreme vengeance scores would be valuable. Finally, the collisions and violations questions did 
not focus on a specified or limited period of time, meaning that drivers who were licensed for a longer period of time may have had inflated collision and violation counts. This should be resolved in future research by specifying a limited time period (e.g., the previous 12 months); however, the fairly limited age range of the current university student sample likely minimized the impact of this limitation.

\section{IMPLICATIONS}

Driver vengeance has been identified as being significantly associated with driver aggression and violence. By identifying personality and individual difference variables related to driver vengeance, researchers may have a better understanding of how vengeance contributes to roadway altercations and how its predictive value for driver aggression may vary with other aspects of a driver's personality. This, in turn, may assist in the development of educational programs and policies targeting this specific type of aggressive driver (Linden et al., 2010). For instance, the current results suggest that educational campaigns focused on driver vengeance might be more effective if they target male drivers, who are more likely to express a vengeful attitude than female drivers. Likewise, aggressive drivers who are apprehended by the authorities may benefit from a remedial measures program that includes assessments for driver vengeance and related individual difference measures. Aggressive drivers with vengeful attitudes might be asked to complete an educational component within the remedial measures program that specifically targets common cognitions associated with vengeful behavior (Lennon \& Watson, 2011). Aggressive and vengeful drivers who are identified as high in narcissism (particularly those who are diagnosed with narcissistic personality disorder) may benefit from psychotherapy.

\section{FUTURE RESEARCH}

Future investigations of this research issue will want to examine other personality and individual difference measures that may be relevant to driver vengeance. Moreover, future 
research will also want to include measures of driver anger, aggression, and violence to determine the nature of the relationship between all of these related constructs. Mediational analysis may be the next most logical step, assessing vengeance as a mediator between more general personality constructs such as narcissism or impulsivity on the one hand and driver aggression and violence on the other hand. Future studies may also want to include cognitive measures such as attribution, appraisal of stress, and hostile thinking (e.g., see Nesbit \& Conger, 2012). Finally, future research should also employ experimental methods or relate driver vengeance to behavioral measures of driver aggression and violence. 


\section{REFERENCES}

Aiken, L. S., \& West, S. G. (1991). Multiple regression: Testing and interpreting interactions. Newbury Park, CA.

Barkley, R. A., \& Cox, D. (2007). A review of driving risks and impairments associated with attention-deficit/hyperactivity disorder and the effects of stimulant medication on driving performance. Journal of Safety Research, 38, 113-128.

Britt, T. W., \& Garrity, M. J. (2006). Attributions and personality as predictors of the road rage response. British Journal of Social Psychology, 45, 127-147.

Bushman, B., \& Baumeister, R. (1998). Threatened egotism, narcissism, self-esteem, and direct and displaced aggression: Does self-love or self-hate lead to violence? Journal of Personality and Social Psychology, 75, 219-229.

Cota-McKinley, A. L., Woody, W. D., \& Bell, P. A. (2001). Vengeance: Effects of gender, age, and religious background. Aggressive Behavior, 27, 343-350.

Dahlen, E. R., Martin, R. C., Ragan, K., \& Kuhlman, M. M. (2005). Driving anger, sensation seeking, impulsiveness, and boredom proneness in the prediction of unsafe driving. Accident Analysis and Prevention, 37, 341-348.

DePasquale, J. P., Geller, E. S., Clarke, S. W., \& Littleton, L. C. (2001). Measuring road rage: Development of the Propensity for Angry Driving Scale. Journal of Safety Research, 32, $1-16$.

Eagly, A. H., \& Steffen, V. J. (1986). Gender and aggressive behaviour: A meta-analytic review of the social psychological literature. Psychological Bulletin, 100, 309-330.

Ellison, P. A., Govern, J. M., Petri, H. L., \& Figler, M. H. (1995). Anonymity and aggressive driving behaviour: A field study. Journal of Social Behavior and Personality, 10, 265-272. 
Ellison-Potter, P., Bell, P., \& Deffenbacher, J. (2001). The effects of trait driving anger, anonymity, and aggressive stimuli on aggressive driving behavior. Journal of Applied Social Psychology, 31, 431-443.

Eysenck, S., Pearson, P. R., Easting, G., \& Allsopp, J. F. (1985). Age norms for impulsiveness, venturesomeness and empathy in adults. Personality and Individual Differences, 6, 613619.

Field. A. (2005). Discovering Statistics using SPSS. SAGE Publications Inc., Thousand Oaks, CA.

Galovski, T., Blanchard, E. B., \& Veazey, C. (2002). Intermittent explosive disorder and other psychiatric co-morbidity among court-referred and self-referred aggressive drivers. Behaviour Research and Therapy, 40, 641-651.

Gulian, E., Matthews, G., Glendon, A. I., Davies, D. R., \& Debney, L. M. (1989). Dimensions of driver stress. Ergonomics, 32, 585-602.

Hennessy, D. L. (2008). The impact of driving vengeance and perceived control on state driver aggression in low and high congestion. In P. O. Inweldi (Ed.), Transportation Research Trends (pp. 201-213). New York: Nova Science Publishers.

Hennessy, D. L. (2013). Personal predictors of driver aggression in Moscow. In B. C. Guevara and N. A. Becerra (Eds.), Psychology of aggression: New research (pp. 79-98). New York: Nova Science Publishers.

Hennessy, D. A., \& Wiesenthal, D. L. (1997). The relationship between traffic congestion, driver stress and direct versus indirect coping behaviours. Ergonomics, 40, 348-361.

Hennessy, D. A., \& Wiesenthal, D. L. (2001a). Further validation of the Driving Vengeance Questionnaire. Violence and Victims, 16, 565-573. 
Hennessy, D. A., \& Wiesenthal, D. L. (2001b). Gender, driver aggression, and driver violence: An applied evaluation. Sex Roles, 44, 661-676.

Hennessy, D. A., \& Wiesenthal, D. L. (2002a). Aggression, violence, and vengeance among male and female drivers. Transportation Quarterly, 56, 65-75.

Hennessy, D. A., \& Wiesenthal, D. L. (2002b). The relationship between driver aggression, violence, and vengeance. Violence \& Victims, 17, 707-718.

Hennessy, D. A., \& Wiesenthal, D. L. (2004). Age and vengeance as predictors of mild driver aggression. Violence and Victims, 19, 469-477.

Hennessy, D. A., \& Wiesenthal, D. L. (2005a). Driving vengeance and willful violations: Clustering of problem driving attitudes. Journal of Applied Social Psychology, 35, 61-79.

Hennessy, D. A. \& Wiesenthal, D. L., (Eds.). (2005b). Contemporary issues in road user behavior and traffic safety. Hauppauge, NY: Nova Science Publishers.

Hennessy, D. A., Wiesenthal, D. L., \& Piccione, G. (2001, June). Aggressive driving, stress, and vengeance in Canada and Italy. Paper presented at the 12th Canadian Multidisciplinary Road Safety Conference, London, Ontario, Canada.

Hennessy, D. A., Wiesenthal, D. L., Wickens, C. M., \& Lustman, M. (2004). The impact of gender and stress on traffic aggression: Are we really that different?. In J. P. Morgan (Ed.), Focus on aggression research (pp. 157-174). Hauppauge, NY: Nova Science Publishers.

Lennon, A., \& Watson, B. (2011). “Teaching them a lesson?” A qualitative exploration of underlying motivations for driver aggression. Accident Analysis and Prevention, 43, $2200-2208$.

Li, F., Li, C., Long, Y., Zhan, C., \& Hennessy, D. A. (2004). Reliability and validity of aggressive driving measures in China. Traffic Injury Prevention, 5, 349-355. 
Linden, R., Mann, R. E., Smart, R. G., Vingilis, E., Solomon, R., Chamberlain, E., ...Wiesenthal, D. L. (2010). Research, policy development and progress: Antisocial behaviour and the automobile. Canadian Public Policy, 26, S81-S93.

Lustman, M., Wiesenthal, D. L., \& Flett, G. L. (2010). Narcissism and aggressive driving: Is an inflated view of the self a road hazard? Journal of Applied Social Psychology, 40, 14231449.

Malta, L. S., Blanchard, E. B., Freidenberg, B. M., Galovski, T. E., Karl, A., \& Holzapfel, S. R. (2001). Psychophysiological reactivity of aggressive drivers: An exploratory study. Applied Psychophysiology and Biofeedback, 26, 95-116.

Marsh, P., \& Collett, P. (1987). The car as a weapon. Et cetera, 44, 146-151.

Matthews, G., Dorn, L., \& Glendon, A. I. (1991). Personality correlates of driver stress. Personality and Individual Differences, 12, 535-549.

Matthews, G., Dorn, L., Hoyes, W., Davies, D. R., Glendon, A. I., \& Taylor, R. G. (1998). Driver stress and performance on a driving simulator. Human Factors, 40, 136-149.

McCullough, M. C., Bellah, C. G., Kilpatrick, S. D., \& Johnson, J. L. (2001). Vengefulness: Relationships with forgiveness, rumination, well-being, and the Big Five. Personality and Social Psychology Bulletin, 27, 601-610.

Mesken, J., Hagenzieker, M. P., Rothengater, T., \& De Waard, D. (2007). Frequency, determinants, and consequences of different drivers' emotions: An on-the-road study using self-reports, (observed) behaviour, and physiology. Transportation Research Part F, 10, $458-475$.

Neighbors, C., Vietor, N. A., \& Knee, C. R. (2002). A motivational model of driving anger and aggression. Personality and Social Psychology Bulletin, 28, 324-335. 
Nesbit, S. M., \& Conger, J. C. (2012). Predicting aggressive driving behavior from anger and negative cognitions. Transportation Research Part F, 15, 710-718.

Nunnally, J. C., \& Bernstein, I. H. (1994). Psychometric theory (3rd ed.). Toronto, ON: McGrawHill, Inc.

O’Brien, F., \& Gormley, M. (2013). The contribution of inhibitory deficits to dangerous driving among young people. Accident Analysis and Prevention, 51, 238-242.

Przepiórka, A. M., Blachnio, A., \& Wiesenthal, D. L. (2014). The determinants of driving aggression among Polish drivers. Transportation Research Part F: Traffic Psychology and Behaviour, 27, 69-80.

Raskin, R., \& Terry, H. (1988). A principal-components analysis of the Narcissistic Personality Inventory and further evidence of its construct validation. Journal of Personality and Social Psychology, 54, 890-902.

Rhodewalt, F., \& Morf, C. C. (1998). On self-aggrandizement and anger: A temporal analysis of narcissism and affective reactions to success and failure. Journal of Personality and Social Psychology, 74, 672-685.

Roseborough, J., Wiesenthal, D. L., Flett, G. L., \& Cribbie, R. A. (2011, May). The belief in an unjust world and narcissism - The influence of personality on perceptions of injustice, driving anger, and aggressive driving. Paper presented at the $21^{\text {st }}$ Canadian Multidisciplinary Road Safety Conference, Halifax, Nova Scotia, Canada.

Rothe, J. P. (1994). Beyond traffic safety. New Brunswick, NJ: Transaction Publishers. Ryb, G. E., Dischinger, P. C., Kufera, J. A., \& Read, K. M. (2006). Risk perception and impulsivity: Association with risky behaviors and substance abuse disorders. Accident Analysis and Prevention, 38, 567-573. 
Schreer, G. E. (2002). Narcissism and aggression: Is inflated self-esteem related to aggressive driving? North American Journal of Psychology, 4, 333-342.

Shin, P. C., Hallett, D., Chipman, M. L., Tator, C., \& Granton, J. T. (2005). Unsafe driving in North American automobile commercials. Journal of Public Health, 27, 318-325.

Smart, R. G., Mann, R. E., \& Goldbloom, D. S. (2005). Road rage: Are our patients driving angry?. Psychiatric Times, April, 25-26, 31.

Stuckless, N., \& Goranson, R. (1992). The vengeance scale: Development of a measure of attitudes toward revenge. Journal of Social Behavior and Personality, 7, 25-42.

Tabachnick, B. G., \& Fidell, L. S. (2001). Using multivariate statistics (4 ${ }^{\text {th }}$ ed.). Toronto: Allyn and Bacon.

Underwood, G., Chapman, P., Wright, S., \& Crundall, D. (1999). Anger while driving. Transportation Research Part F, 2, 55-68.

Whitley, B. E., Jr. (1996). Principles of research in behavioral science. Toronto: Mayfield Publishing Company.

Wickens, C. M., Mann, R. E., Stoduto, G., Ialomiteanu, A., \& Smart, R. G. (2011). Age group differences in self-reported aggressive driving perpetration and victimization. Transportation Research Part F, 14, 400-412.

Wickens, C. M., Roseborough, J. E. W., Hall, A., \& Wiesenthal, D. L. (2013). Anger-provoking events in driving diaries: A content analysis. Transportation Research Part F, 19, 108120.

Wickens, C. M., Toplak, M. E., \& Wiesenthal, D. L. (2008). Cognitive failures as predictors of driving errors, lapses, and violations. Accident Analysis and Prevention, 40, 1223-1233. 
Wickens, C. M., \& Wiesenthal, D. L. (2005). State driver stress as a function of occupational stress, traffic congestion, and trait stress susceptibility. Journal of Applied Biobehavioral Research, 10, 83-97.

Wickens, C. M., Wiesenthal, D. L., Flora, D. B., \& Flett, G. L. (2011). Understanding driver anger and aggression: Attributional theory in the driving environment. Journal of Experimental Psychology: Applied, 17, 354-370

Wiesenthal, D. L., Hennessy, D., \& Gibson, P. M. (2000). The Driving Vengeance Questionnaire (DVQ): The development of a scale to measure deviant drivers' attitudes. Violence and Victims, 15, 115-136.

Wiesenthal, D. L., Lustman, M., \& Roseborough, J. (in press). Aggressive driving. In A. Smiley (Ed.), Human factors in traffic safety (3rd ed.). Tucson, AZ: Lawyers \& Judges Publishing Company.

Wiesenthal, D. L., \& Singhal, D. M. (2012). Evolutionary psychology, demography and driver safety research: A theoretical synthesis. In S. Craig Roberts (Ed.), Applied evolutionary psychology (pp.399-413). Oxford, UK: Oxford University Press.

Williams, J., Tregear, S., \& Amana, A. (2011, June). Psychiatric disorders and driver safety: A systematic review. Paper presented at the Sixth International Driving Symposium on Human Factors in Driver Assessment, Training and Vehicle Design, Olympic Valley-Lake Tahoe, California.

Wilson, M., \& Daly, M. (1985). Competiveness, risk taking, and violence: The young male syndrome. Ethology and Sociobiology, 6, 59-73. 


\section{Acknowledgments}

Dr. Wickens was supported by a student scholarship from the Canadian Transportation Research Forum and by postdoctoral fellowships from the Social Sciences and Humanities Research Council and the Centre for Addiction and Mental Health. Prof. Wiesenthal held a Social Sciences and Humanities Research Council grant, which facilitated this research. The authors would like to thank Vadim Paskarou, Arathi Packiyanathan, Meenu Minhas, Lisa Hilliard, Siamak Riazzi, and Sara Howard for their assistance with participant recruitment and data entry. An earlier version of this manuscript was presented at the Canadian Multidisciplinary Road Safety Conference in Montreal, Canada. 
TABLE 1. Bivariate Correlations and Reliability Analysis

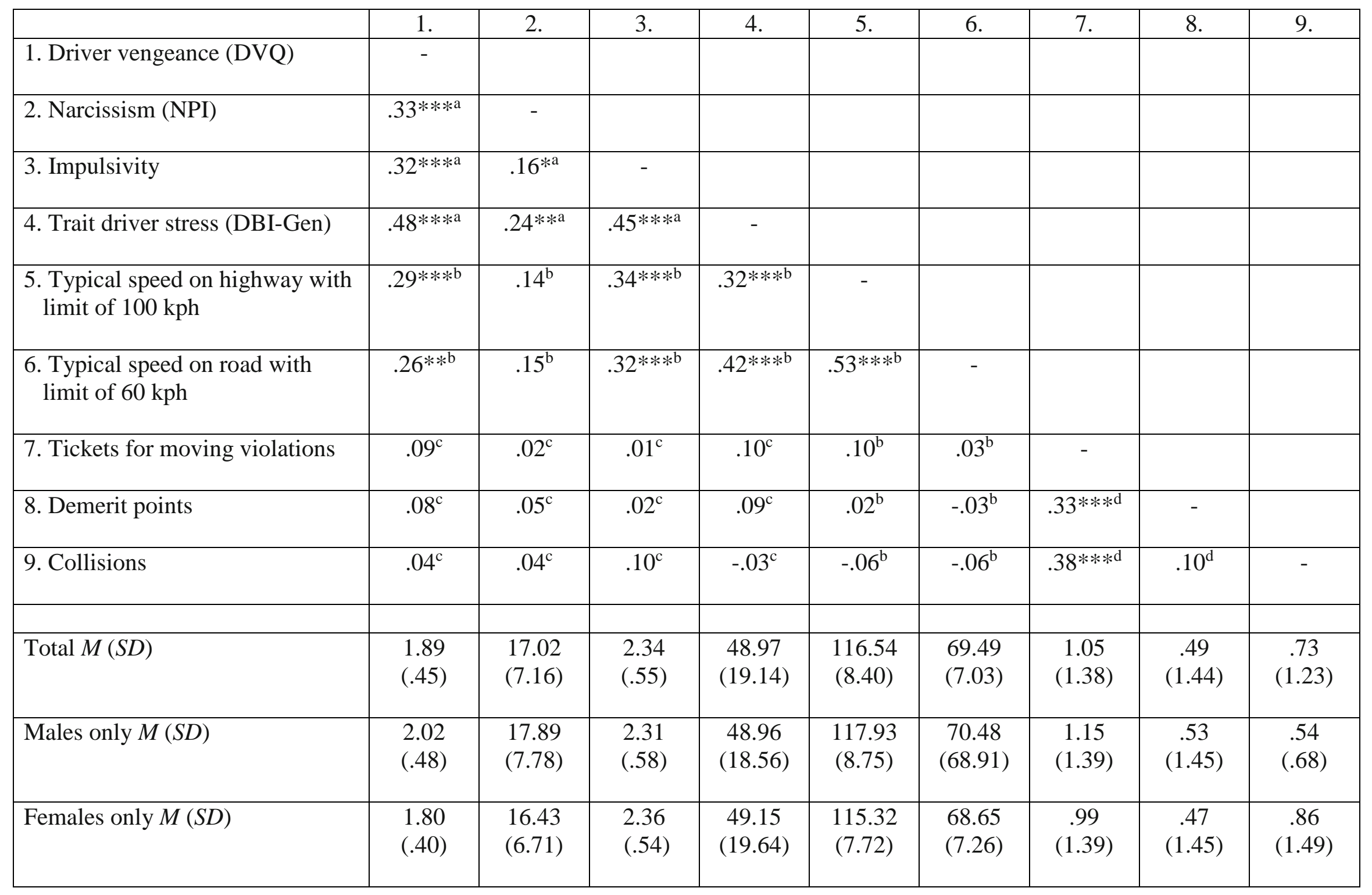




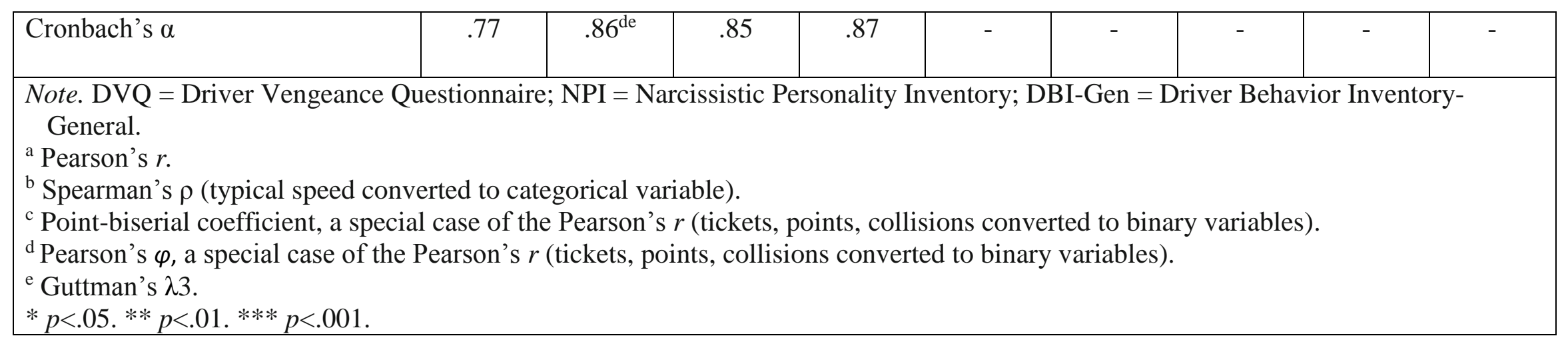


TABLE 2. Mean Driver Vengeance Questionnaire Scores as a Function of Self-Reported Collisions and Violations

\begin{tabular}{|c|c|c|c|c|}
\hline & & $n$ & $M$ & $S D$ \\
\hline \multirow[t]{2}{*}{ Collisions } & None & 93 & 1.87 & .44 \\
\hline & $1+$ & 77 & 1.91 & .47 \\
\hline \multirow[t]{2}{*}{ Tickets } & None & 84 & 1.85 & .49 \\
\hline & $1+$ & 86 & 1.93 & .41 \\
\hline \multirow[t]{2}{*}{ Demerit Points } & None & 145 & 1.88 & .45 \\
\hline & $1+$ & 23 & 1.99 & .46 \\
\hline \multirow[t]{3}{*}{ Speed on $60-\mathrm{kph}$ roads } & Up to $65 \mathrm{kph}$ & 59 & 1.71 & .41 \\
\hline & $66-70 \mathrm{kph}$ & 67 & 1.98 & .44 \\
\hline & $71+\mathrm{kph}$ & 44 & 1.99 & .46 \\
\hline \multirow[t]{3}{*}{ Speed on $100-k p h$ highways } & Up to $110 \mathrm{kph}$ & 61 & 1.75 & .45 \\
\hline & $111-120 \mathrm{kph}$ & 86 & 1.94 & .42 \\
\hline & $121+\mathrm{kph}$ & 23 & 2.08 & .45 \\
\hline
\end{tabular}


TABLE 3. Hierarchical Regression of the Predictors of Driving Vengeance

\begin{tabular}{|c|c|c|c|c|c|c|}
\hline Variable & $B$ & $S E(B)$ & $\mathrm{B}$ & $t$ & Part Correlation & Adjusted $R^{2}$ \\
\hline$\overline{\text { Step } 1}$ & & & & & & $.062 * *$ \\
\hline (Constant) & 1.91 & .038 & & $50.47 * * *$ & & \\
\hline Gender & 0.12 & .038 & .26 & $3.24 * *$ & .26 & \\
\hline \multicolumn{7}{|l|}{ Step 2} \\
\hline (Constant) & 1.91 & .036 & & $52.79 * * *$ & & $.146^{* * *}$ \\
\hline Gender & .011 & .036 & .22 & $2.87 * *$ & .22 & \\
\hline Narcissism & 0.02 & .005 & .30 & $3.87 * * *$ & .30 & \\
\hline Step 3 & & & & & & $.214 * * *$ \\
\hline (Constant) & 1.92 & .035 & & $55.10 * * *$ & & \\
\hline Gender & 0.11 & .035 & .24 & $3.15^{* *}$ & .23 & \\
\hline Narcissism & 0.02 & .005 & .26 & $3.37 * *$ & .25 & \\
\hline Impulsivity & 0.23 & .064 & .27 & $3.62^{* * *}$ & .27 & \\
\hline Step 4 & & & & & & $.340 * * *$ \\
\hline (Constant) & 1.91 & .032 & & $59.91 * * *$ & & \\
\hline Gender & 0.12 & .032 & .25 & $3.68 * * *$ & .25 & \\
\hline Narcissism & 0.01 & .005 & .19 & $2.61^{*}$ & .18 & \\
\hline Impulsivity & 0.09 & .065 & .10 & 1.31 & .09 & \\
\hline Trait Driver Stress & 0.01 & .002 & .41 & $5.26^{* * * *}$ & .36 & \\
\hline
\end{tabular}

Note. $F(4,139)=19.40, p<.001$.

$* p<.05 . * * p<.01 . * * * p \leq .001$. 